\title{
Procedure to Enhance the Recovery Rate of Fungus Gnat, Bradysia sp. nr. coprophila Lintner (Diptera: Sciaridae) Adults from Growing Medium
}

\author{
Raymond A. Cloyd ${ }^{1}$ \\ Kansas State University, Department of Entomology, 123 Waters Hall, \\ Manhattan, KS 66506-4004
}

Amy Dickinson

Division of Biodiversity and Ecological Entomology, Illinois Natural History

Survey, Champaign, IL

Additional index words. recovery rate, efficacy, growing medium, survival, water volume

Abstract. Fungus gnats, Bradysia spp., are major insect pests in greenhouses and interiorscapes. Management typically involves the use of either insecticides or biological control agents such as entomopathogenic nematodes. Efficacy trials provide information to greenhouse producers on the effectiveness of these management options. However, a simple procedure that rapidly evaluates the performance of control products against fungus gnat larvae is needed. Because fungus gnat larvae inhabit the growing medium, excess or deficient growing medium moisture may reduce adult fungus gnat emergence, thus confounding effects from efficacy trial treatments. Therefore, it is important to determine the amount of moisture and moisture content that results in the highest recovery of fungus gnat adults. We conducted two replicated experiments in a completely randomized design using a range of initial water volumes (treatments) and two larval stages (second and third) of the fungus gnat, Bradysia sp. nr. coprophila. The success of the procedure was based on the number of fungus gnat adults that emerged per treatment. In the first experiment, initial water volumes of $0,25,50,75,100,150$, and 200 mL were applied to $300 \mathrm{~mL}$ of a soilless growing medium consisting of $50 \%$ composted pine bark, $20 \%$ Canadian sphagnum peatmoss, $10 \%$ perlite, and $20 \%$ medium coarse vermiculite (SB300 Universal Mix). In general, the highest mean numbers (range, 11.2 to 14.6) of fungus gnat adults were recovered from growing medium treated with 50,75 , and $100 \mathrm{~mL}$ of water. In the second experiment, initial water volumes (treatments) of 50, 55, $60,65,70$, and $75 \mathrm{~mL}$ were applied to $300 \mathrm{~mL}$ of the soilless growing medium (SB300 Universal Mix). There were no significant differences in the mean number of fungus gnat adults recovered regardless of the larval instar (second instar: 15.8 to 17.7; third instar: 14.4 to 17.4). The final percent moisture content ranged from $65 \%$ to $68 \%$ for the second instars and $56 \%$ to $66 \%$ for third instars. This study demonstrates that the highest number of fungus gnat adults may be recovered from soilless growing medium (SB300 Universal Mix) treated with between 50 and $75 \mathrm{~mL}$ of water, thus enhancing the confidence in any data set generated when evaluating insecticides or biological control agents for control of fungus gnats.

The soft-bodied larvae of fungus gnats (Bradysia spp.) reside in growing medium and require constant moisture for survival (Ellisor, 1934). Moisture content is an essential factor responsible for the development and survival of insect stages that reside in the soil or growing medium (Villani and Wright, 1990). Moisture content has been shown to affect the population growth, development, and survival of various subterranean arthro-

Received for publication 26 Dec. 2007. Accepted for publication 18 Mar. 2008.

We acknowledge the Fred C. Gloeckner Foundation for providing financial support for this study.

${ }^{1}$ To whom reprint requests should be addressed; e-mail rcloyd@ksu.edu conditions (less than $20 \%$ gravimetric percent soil moisture content) (Villani and Wright, 1990).

Moisture content of the growing medium surface has been implicated in influencing shore fly, Scatella stagnalis Fallen, population development (Jacobson et al., 1999). However, relatively minimal information exists in the literature on the effect of growing medium moisture content on the survival and development of fungus gnats, Bradysia spp., which is important when conducting efficacy trials. Efficacy trials are designed to evaluate the ability of insecticides and biological control agents to regulate fungus gnat populations. Therefore, it is important to use a procedure that results in the highest recovery rates of adults so that the effectiveness of an insecticide or biological control agent can be accurately assessed. In addition, this will increase the confidence in the data so that any negative effects may be attributed to the treatments and not the result of confounding effects associated with inadequate moisture content. As such, the purpose of this study was to develop a procedure that results in the highest recovery rate of fungus gnat adults when conducting efficacy trials on fungus gnat larvae.

\section{Materials and Methods}

Expt. 1: Effect of water volumes ranging from 0 to $200 \mathrm{~mL}$ on fungus gnat adult emergence. Fungus gnat adults used for both experiments were obtained from laboratory colonies located at the University of Illinois, Urbana, IL (Cabrera et al., 2005) and reared in SB300 Universal Professional Growing Mix (Sun Gro Horticulture, Bellevue, WA). Specimens from the colony were identified as Bradysia sp. nr. coprophila (Linter) by Raymond J. Gagne, Systematic Entomology Department Laboratory, USDA. Voucher specimens are located in the Illinois Natural History Survey Insect Collection (\#2289622932, 32015-32021).

The experiment was set up as a completely randomized design with seven replications per water volume treatment for each fungus gnat instar (second and third). We used a growing medium consisting of $50 \%$ composted pine bark, 20\% Canadian sphagnum peatmoss, $10 \%$ perlite, and $20 \%$ medium coarse vermiculite (SB300 Universal Mix; Strong-Lite Horticulture Products, Pine Bluff, AK). The growing medium was pasteurized by heating, in $5.8-\mathrm{L}$ increments, at full power for $10 \mathrm{~min}$ in a microwave $(850-\mathrm{W}$ output). The growing medium was then measured out in $300-\mathrm{mL}$ quantities and amended with $0.85 \mathrm{~g}$ of raw oatmeal (The Quaker Oats Company, Chicago). The growing medium was then placed into $0.50-\mathrm{L}$ polypropylene deli squat containers (FabriKal Corp., Kalamazoo, MI). One of seven deionized water treatments was applied to each of $300 \mathrm{~mL}$ volume of soilless growing medium amended with oatmeal: $0,25,50,75$, 100,150 , and $200 \mathrm{~mL}$. After application of the water treatments, a lid modified with 
antivirus insect screening $50 \times 24(0.2 \times 0.8$ $\mathrm{mm}$; Greentek, Edgerton, WI) was securely fastened to the containers. This prevented any fungus gnat adults from escaping. The containers were placed randomly in a controlled environmental growth chamber (Kysor Sherer environmental chamber, model Cel36-10; Sherer Environmental Warren/Sherer Division, Marshall, WI) set at $23 \pm 3{ }^{\circ} \mathrm{C}$ and $0: 24$ (light : dark) h photoperiod. After $48 \mathrm{~h}$, as described in Cloyd and Dickinson (2006), 20 7-d-old second instar and 11-d-old third instar fungus gnat larvae were placed onto the growing medium surface. The deli squat container treatments, with the lids securely fastened, were then returned and randomly arranged in the environmental growth chamber. After $24 \mathrm{~h}, 60 \mathrm{~mL}$ of deionized water was added as a drench to each deli squat container. For the remainder of the study, each container received a weekly application of 60 $\mathrm{mL}$ of water applied to a dish placed beneath the container, which the growing medium absorbed through small holes perforated in the base of the container. These holes were small enough to prevent fungus gnat larvae from escaping. Yellow sticky cards $(2.5 \times 2.5$ $\mathrm{cm})$ were placed on the growing medium surface to capture fungus gnat adults that emerged. The experiment was completed when the fungus gnats were $\approx 31 \mathrm{~d}$ old, at which time the adults had finished emerging. The sticky cards were counted and the number of adults that had emerged was recorded.

Data were analyzed using SAS Systems for Windows, version 8.2 (SAS Institute, 2002). All data were analyzed using a oneway analysis of variance (ANOVA) with water volume as the treatment main effect. Significant treatment means for the number of fungus gnat adults recovered on the yellow sticky cards were separated using a Fisher's protected least significant difference (LSD) test at $P \leq 0.05$.

The initial and final growing medium moisture content were determined. Five petri dishes $(60 \times 15 \mathrm{~mm})$ of growing medium were processed to assess percent moisture content. After the growing medium was sterilized, samples were weighed and placed into an oven set at $60 \pm 2{ }^{\circ} \mathrm{C}$ for $7 \mathrm{~d}$. After the 7 -d period, the weight of the samples was constant and this final weight was recorded and percent moisture content calculated. The formula used to obtain percent moisture content was as follows:

$$
(\mathrm{A}-\mathrm{B})-(\mathrm{C}-\mathrm{B}) /(\mathrm{A}-\mathrm{B}) \times 100
$$

where $\mathrm{A}=$ initial weight $(\mathrm{g})$ (petri dish + moist growing medium), $\mathrm{B}=$ weight $(\mathrm{g})$ of petri dish, and $\mathrm{C}=$ final weight $(\mathrm{g})$ (petri dish + dry growing medium).

It is important to note that the formula, in the context of our study, used the moist growing medium sample as the denominator.

Expt. 2: Effect of water volumes ranging from 50 to $75 \mathrm{~mL}$ on fungus gnat adult emergence. Based on the results obtained in the first experiment, we used a narrower range of initial water volumes (50 to $75 \mathrm{~mL}$ ). There were five replications per water volume (treatment) for each fungus gnat instar (second and third instar). The procedures were similar to those described for Expt. 1 except that the initial deionized water volume per $300 \mathrm{~mL}$ growing medium treatments were $50,55,60,65,70$, and $75 \mathrm{~mL}$. Data were analyzed using the same procedures as specified in the first experiment.

\section{Results}

Expt. 1: Effect of water volumes ranging from 0 to $200 \mathrm{~mL}$ on fungus gnat adult emergence. Water volume (treatment) was significant for the mean number of adult fungus gnats that emerged from growing medium inoculated with second and third instars (second instar: $F=13.48$; df $=6,55$; $P<0.0001$ and third instar: $F=5.92 ; \mathrm{df}=6$, 55; $P=0.0001$ ) (Table 1). The number of adult fungus gnats that emerged from the growing medium was significantly higher for the 50-, 75-, and 100-mL treatments than the other water volumes for second instar fungus gnats (Table 1), which resulted in fungus gnat adult recovery rates ranging from $71 \%$ to $73 \%$. For the third instar, a numerically higher mean number $(14.5 \pm 0.7$, mean \pm $\mathrm{SE}$ ) of adult fungus gnats emerged from growing medium initially moistened with $75 \mathrm{~mL}$ of water than the other water volume treatments (Table 1) with a $73 \%$ recovery rate. The $75-\mathrm{mL}$ initial water volume treatment was significantly different from the other treatments with the exception of the $100-\mathrm{mL}$ initial water volume treatment (Table 1 ). The mean initial and final percent moisture contents across the treatments for second instar fungus gnat larvae were $69 \%$ and $67 \%$, respectively. The mean initial and final percent moisture contents across the treatments for third instar fungus gnat larvae were $69 \%$ and $61 \%$, respectively.

Expt. 2: Effect of water volumes ranging from 50 to $75 \mathrm{~mL}$ on fungus gnat adult emergence. Water volume (treatment) was

Table 1. Mean ( \pm SEM) number of adult fungus gnats (Bradysia sp. nr. coprophila) that emerged, based on yellow sticky card counts, from deli squat containers with growing medium treated with different volumes of deionized water before inoculation with second and third instar fungus gnat larvae for Expt. 1. ${ }^{\mathrm{z}}$

\begin{tabular}{lcc}
\hline $\begin{array}{l}\text { Initial } \\
\text { water } \\
\text { volume }\end{array}$ & $\begin{array}{c}\text { Second instar } \\
\text { no. of FG adults } \\
\text { (mean } \pm \text { SEM) }\end{array}$ & $\begin{array}{c}\text { Third instar } \\
\text { no. of FG adults } \\
\text { (mean } \pm \text { SEM) }\end{array}$ \\
\hline $0 \mathrm{~mL}$ & $8.7 \pm 1.6 \mathrm{~b}^{\mathrm{y}}$ & $7.3 \pm 1.2 \mathrm{c}$ \\
$25 \mathrm{~mL}$ & $9.5 \pm 1.3 \mathrm{~b}$ & $10.0 \pm 1.4 \mathrm{bc}$ \\
$50 \mathrm{~mL}$ & $14.6 \pm 0.6 \mathrm{a}$ & $11.2 \pm 0.9 \mathrm{~b}$ \\
$75 \mathrm{~mL}$ & $14.0 \pm 0.5 \mathrm{a}$ & $14.5 \pm 0.7 \mathrm{a}$ \\
$100 \mathrm{~mL}$ & $14.2 \pm 0.9 \mathrm{a}$ & $12.5 \pm 0.6 \mathrm{ab}$ \\
$150 \mathrm{~mL}$ & $8.0 \pm 1.3 \mathrm{~b}$ & $9.6 \pm 1.1 \mathrm{bc}$ \\
$200 \mathrm{~mL}$ & $3.7 \pm 0.9 \mathrm{c}$ & $8.1 \pm 0.8 \mathrm{c}$ \\
\hline
\end{tabular}

${ }^{\mathrm{z}}$ Each deli squat container was inoculated with either 20 second or third instar fungus gnats; $\mathrm{n}=7$ replications per treatment (initial water volume).

${ }^{\mathrm{y}}$ Means followed by a common letter within a column are not significantly different $(P=0.05)$ as determined by Fisher's protected least significance difference test. not significant for the mean number of fungus gnat adults that emerged from the growing medium inoculated with either second $(F=$ $0.36 ; \mathrm{df}=5,59 ; P=0.875)$ or third $(F=1.34$; $\mathrm{df}=5,59 ; P=0.260)$ instars as all six initial water volume treatments resulted in means of 15.8 to 17.7 fungus gnat adults emerging from the growing medium associated with second instars (Table 2) with adult recovery rates of $79 \%$ to $88 \%$. A mean of 14.4 to 17.4 fungus gnat adults emerged from the growing medium associated with third instars (Table 2 ) with adult recovery rates of $79 \%$ to $88 \%$. The mean initial and final percent moisture contents across the treatments for second instar fungus gnat larvae were $68 \%$ and $66 \%$, respectively. The mean initial and final percent moisture contents across the treatments for third instar fungus gnat larvae were $68 \%$ and $60 \%$, respectively.

\section{Discussion}

This study has quantified a procedure to enhance the recovery rate of fungus gnat adults from growing medium. We determined that initially applying water volumes between 50 and $75 \mathrm{~mL}$ to $300 \mathrm{~mL}$ of growing medium (SB300 Universal Mix) results in the highest recovery rate of fungus gnat adults. This information may increase the validity of efficacy trials conducted with fungus gnats and other soilborne arthropods with subterranean life stages. Although we did not directly measure fungus gnat larval mortality, fungus gnat adult emergence is an indirect method to assess mortality of fungus gnat larvae. There is a quantitative procedure designed to extract (recover) fungus gnat larvae from growing medium (Zaborski and Cloyd, 2004); however, this procedure requires more equipment and labor time than the procedure designated in this study. Additionally, growing medium moisture content may affect the extraction of fungus gnat larvae.

In our study, we minimized the influence of certain factors, which may have impacted

Table 2. Mean ( \pm SEM) number of adult fungus gnats (Bradysia sp. nr. coprophila) that emerged, based on yellow sticky card counts, from deli squat containers with growing medium treated with different volumes of deionized water before inoculation with second and third instar fungus gnat larvae for Expt. 2. ${ }^{\mathrm{z}}$

\begin{tabular}{lcc}
\hline $\begin{array}{l}\text { Initial } \\
\text { water } \\
\text { volume }\end{array}$ & $\begin{array}{c}\text { Second instar } \\
\text { no. of FG adults } \\
\text { (mean } \pm \text { SEM) }\end{array}$ & $\begin{array}{c}\text { Third instar } \\
\text { no. of FG adults } \\
\text { (mean } \pm \text { SEM) }\end{array}$ \\
\hline $50 \mathrm{~mL}$ & $15.8 \pm 1.4 \mathrm{a}^{\mathrm{y}}$ & $15.2 \pm 1.3 \mathrm{a}$ \\
$55 \mathrm{~mL}$ & $16.0 \pm 1.7 \mathrm{a}$ & $14.4 \pm 1.0 \mathrm{a}$ \\
$60 \mathrm{~mL}$ & $16.7 \pm 0.6 \mathrm{a}$ & $17.4 \pm 0.7 \mathrm{a}$ \\
$65 \mathrm{~mL}$ & $17.7 \pm 0.8 \mathrm{a}$ & $16.6 \pm 0.5 \mathrm{a}$ \\
$70 \mathrm{~mL}$ & $16.1 \pm 1.1 \mathrm{a}$ & $16.1 \pm 0.8 \mathrm{a}$ \\
$75 \mathrm{~mL}$ & $16.3 \pm 0.7 \mathrm{a}$ & $16.1 \pm 0.7 \mathrm{a}$ \\
\hline
\end{tabular}

${ }^{z}$ Each deli squat container was inoculated with either 20 second or third instar fungus gnats; $\mathrm{n}=5$ replications per treatment (initial water volume). ${ }^{\mathrm{y}}$ Means followed by a common letter within a column are not significantly different $(P=0.05)$ as determined by Fisher's protected least significance difference test. 
larval survival or adult recovery such as environmental chamber microclimate, light intensity, larval escape through the drainage holes, and adult escape through the lids. In addition, our method of incorporating measured volumes of deionized water into the growing medium that has been either microwaved or oven-dried has been used previously (MacDonald and Ellis, 1990).

The results of this study may also be helpful to greenhouse producers in developing management programs that alleviate problems with fungus gnats. For example, recommendations for reducing problems with fungus gnats oftentimes specify allowing the top 2.5 to $5.0 \mathrm{~cm}$ of the growing medium to "dry down" because this supposedly inhibits or decreases acceptance of the growing medium for egg-laying by fungus gnat females (Meers and Cloyd, 2005). In addition, a "dry" growing medium may increase egg mortality after eggs have been laid (Binns, 1973; Hungerford, 1916). This is similar to findings reported for the Southern masked chafer, Cyclocephala immaculata Oliver (Potter, 1983) and sugarcane grubs (Cherry et al., 1990) in which soil moisture content influences egg mortality and oviposition by females.

Brust and House (1990) reported that low soil moisture levels influence survival of the Southern corn rootworm, Diabrotica undecimpunctata howardi Barber, with eggs and first instars most sensitive to low moisture levels, whereas the second and third instars are less affected by low moisture contents. In our study, we did not evaluate the effect of moisture content on the first instar and eggs of the fungus gnat as a result of problems associated with handling mortality.

LaPointe and Shapiro (1999) demonstrated that higher mortality of Diaprepes abbreviatus (L.) larvae occurred at low (20\% to $40 \%$ ) and high ( $80 \%$ ) gravimetric moisture contents. In fact, $80 \%$ soil moisture content delayed development significantly. It was hypothesized that "dry" soil conditions (less than $20 \%$ gravimetric moisture content) may delay development of insects, thus influencing population dynamics. We also observed this in our study with fungus gnat larvae that initial percent moisture contents less than $59 \%$ and greater than $80 \%$, for both larval instars (second and third), resulted in fewer fungus gnat adults emerging from the growing medium than initial percent moisture contents between $63 \%$ and $75 \%$. In addition, the third instar fungus gnat larvae may have a higher tolerance for "dry" conditions than the second instar fungus gnat larvae based on both the final percent moisture content (third instar range: $56 \%$ to $66 \%$; second instar range: $65 \%$ to $68 \%$ ), although the initial percent moisture contents for both larval instars was similar. These results are analogous to those of Esbjerg (1989) in which the first and second instar cutworms (Agrotis segetum Denis and Schiffermuller) were more sensitive to soil moisture content differences than larger (third to sixth) instars. We found that the highest mean recovery rates of adult fungus gnats were obtained at percent moisture contents between $56 \%$ and $71 \%$. This is similar to findings by Olson et al. (2002) in that fungus gnat larvae survival was higher in a peat-based (35\% to $45 \%$ Sphagnum peat) growing medium maintained at $71.2 \%$ and $52.5 \%$ moisture content with lower larval survival values than when the growing medium was maintained at $90 \%$ and less than $34 \%$. However, it is important to note that different formulas used in previous studies to assess percent moisture content may impact what is considered a "dry" growing medium.

The results of our procedure were obtained with SB300 Universal Mix growing medium, which consists of $50 \%$ composted pine bark, $20 \%$ Canadian sphagnum peatmoss, $10 \%$ perlite, and $20 \%$ medium coarse vermiculite. Sphagnum peatmoss is the primary component of greenhouse growing media (Nelson, 2003) absorbing up to $60 \%$ of its total volume of water (Dole and Wilkins, 2005). Composted pine bark is used in growing media to increase aeration (Nelson, 2003). As such, when using $300 \mathrm{~mL}$ of a soilless growing medium with $20 \%$ Canadian sphagnum peatmoss, initial water volumes between 50 and $75 \mathrm{~mL}$ will lead to the highest number of fungus gnat adults recovered. This will enhance the confidence of any data set generated when evaluating insecticides or biological control agents for control of fungus gnat larvae. However, the procedural results may vary when using a growing medium containing a higher percentage of peatmoss or another major component, thus influencing the initial water volume that would need to be applied. Furthermore, an assessment of the recovery rate of fungus gnat adults would have to be conducted.

\section{Literature Cited}

Binns, E.S. 1973. Laboratory rearing, biology and chemical control of the mushroom sciarid Lycoriella auripila (Diptera: Lycoriidae). Ann. Appl. Biol. 73:119-126.

Brust, G.E. and G.J. House. 1990. Effects of soil moisture, texture, and rate of soil drying on egg and larval survival of the Southern corn rootworm (Coleoptera: Chrysomelidae). Environ. Entomol. 19:697-703.

Cabrera, A.R., R.A. Cloyd, and E.R. Zaborski. 2005. Development and reproduction of Stratiolaelaps scimitus (Acari: Laelapidae) with fungus gnat larvae (Diptera: Sciaridae), potworms (Oligochaeta: Enchytraeidae) or Sancassania aff. sphaerogaster (Acari: Acaridae) as the sole food source. Exp. App. Acarol. 36:71-81.

Cherry, R.H., F.J. Coale, and P.S. Porter. 1990 Oviposition and survivorship of sugarcane grubs (Coleoptera: Scarabaeidae) at different soil moistures. J. Econ. Entomol. 83:13551359.

Cloyd, R.A. and A. Dickinson. 2006. Effect of Bacillus thuringiensis subsp. israelensis and neonicotinoid insecticides on the fungus gnat Bradysia sp nr. coprophila (Lintner) (Diptera: Sciaridae). Pest Manag. Sci. 62:171-177.

Dole, J.M. and H.F. Wilkins. 2005. Floriculture principles and species. 2nd Ed. Pearson Prentice Hall, Upper Saddle River, NJ.

Ellisor, L.O. 1934. Notes on the biology and control of Neosciara ocellaris (Comstock) (Diptera, Sciaridae). Iowa State J. Science 9:25-36.

Esbjerg, P. 1989. The influence of soil moisture on mortality and on the damaging effect of second and 6th instar cutworms (Agrotis segetum Schiff, Lep.: Noctuidae). Acta Ecol. Ecol. Appl. 10:335-347.

Hungerford, H.B. 1916. Sciara maggots injurious to potted plants. J. Econ. Entomol. 9:538-549.

Jacobson, R.J., P. Croft, and J. Fenlon. 1999. Scatella stagnalis Fallen (Diptera: Ephydridae): Towards IPM in protected lettuce crops. Integrated Control in Glasshouses, International Organization of Biological Control Bull. 22:117-120.

LaPointe, S.L. and J.P. Shapiro. 1999. Effect of soil moisture on development of Diaprepes abbreviatus (Coleoptera: Curculionidae). Fla. Entomol. 82:291-299.

MacDonald, P.J. and C.R. Ellis. 1990. Survival time of unfed, first-instar western corn rootworm (Coleoptera: Chrysomelidae) and the effects of soil type, moisture, and compaction on their mobility in soil. Environ. Entomol. 19:666-671.

Meers, T.L. and R.A. Cloyd. 2005. Egg-laying preference of female fungus gnat Bradysia sp. nr. coprophila (Diptera: Sciaridae) on three different soilless substrates. J. Econ. Entomol. 98:1937-1942.

Nelson, P.V. 2003. Greenhouse operation and management. 6th Ed. Prentice Hall, Upper, Saddle River, NJ.

Olson, D.L., R.D. Oetting, and M.W. van Iersel. 2002. Effect of soilless potting media and water management on development of fungus gnats (Diptera: Sciaridae) and plant growth. HortScience 37:919-923.

Potter, D.A. 1983. Effect of soil moisture on oviposition, water absorption, and survival of Southern masked chafer (Coleoptera: Scarabaeidae) eggs. Environ. Entomol. 12:12231227.

Riis, L., P. Esbjerg, and A.C. Bellotti. 2005. Influence of temperature and soil moisture on some population growth parameters of Cyrtomenus bergi (Hemiptera: Cydnidae). Fla. Entomol. 88:11-22.

SAS Institute. 2002. SAS/STAT users' guide, version 9.1. SAS Institute, Inc., Cary, NC.

Villani, M.G. and R.J. Wright. 1990. Environmental influences on soil macro arthropod behaviour in agricultural systems. Annu. Rev. Entomol. 35:249-269.

Zaborski, E.R. and R.A. Cloyd. 2004. Method for quantitative sampling of fungus gnat larvae in soilless growing media. J. Econ. Entomol. 97:678-686. 